\title{
Flexural Rigidity in Concrete Beam by using the Crimped Steel Fibers with Rapid Hardening Admixtures
}

\author{
V M Sounthararajan, S. Sivasankar, T.L. Ramadasu
}

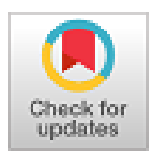

\begin{abstract}
With the increase in the fast track construction industries, the emerging techniques are used for improvement in the concrete strength and its properties. This paper focused on the test results for various mixes of concrete made by replacing $O P C$ cement content with slag and fly ash in varying proportions the use of rapid hardening admixture along with the presence of crimped steel fibers. The flexural strength, crack depth measurement by using the ultrasonic pulse velocity and Elastic modulus of concrete were conducted with different proportions of fly ash (0-15\%) and slag (0-25\%) being replaced in cement and $0-50 \%$ of the fine aggregate is replaced with stone dust. The experimental test results show the volume reduction in flexural members, crack depth measurement by UPV and modulus of elasticity of concrete by scant modulus method was used for various mixes.
\end{abstract}

Keywords: Crack depth, Fly ash, Slag, Strength, Ultrasonic pulse velocity

\section{INTRODUCTION}

In the present days, civil engineering is not only confined to structural construction and architectural designs but engineers are putting great efforts in making green concrete innovation projects and sustainable buildings which have many economic, social and environmental benefits. In this paper, attempts have been made on making green concrete by replacing cement with byproducts of industrial waste [1-3]. As concrete is one of the most widely used material in the construction of buildings, globally a total of about 25gigatonnes of cement is used annually for the development of the structures this increases the level of carbon dioxide which results in the greenhouse gases to reduce this the amount of cement used

Revised Manuscript Received on August 30, 2019.

* Correspondence Author

Dr. VM Sounthararajan*, Professor, Department of Civil Engineering, CMR Technical Campus, Kandlakoya, Medchal Road, Hyderabad, Telangana, India. Email: researchsoundar@yahoo.in

Dr. S. Sivasankar, Associate Professor, Department of Civil Engineering CMR Technical Campus, Kandlakoya, Medchal Road, Hyderabad, Telangana, India. Email: drsssphd@gmail.com

Dr. TL Ramadasu, Professor, Department of Civil Engineering, CMR Technical Campus, Kandlakoya, Medchal Road, Hyderabad, Telangana, India. Email: ramadasjntu@gmail.com

(C) The Authors. Published by Blue Eyes Intelligence Engineering and Sciences Publication (BEIESP). This is an open access article under the CC BY-NC-ND license (http://creativecommons.org/licenses/by-nc-nd/4.0/) is partially replaced with fly ash (0-15\%) and slag (0-25\%) waste by-products and which replace cement in the best way and obtain a maximum strength [4-8].

The mechanical properties of the concrete as such as bending stress of fibre reinforced concrete which improves with an increase in the percentages of steel fibre. The steel fibres prevent the early deforming of the beams and increase the durability of the structure [9-12]. The NDT methods for measuring the strength of a structure are not accurate but can help in correlating the values which can help in estimating the strength of the structure and also useful for analyzing the concrete characteristics and its homogeneity. [13-16] The NDT test was adopted for testing the beams for determining the quality and cracking efficiency. Also, the quality assessments of the structural building construction are basically depended on the usage of material characteristics and also maintain the serviceability of the structures. Further, to monitor the velocity for various elements by using the UPV techniques to calculate the static and dynamic modulus of elasticity of concrete works as a good indicator in concrete deterioration [17-20].

\section{MATERIAL USED}

\section{A. Cement:}

The cement which gains the strength on hydration and holds the aggregate in position to form a structure. All type of mix proportions of concrete used for OPC-53 grade of cement for casting the concrete and testing at different age of curing. The necessity of initial lab test results for OPC as given in Table 1.

Table- I: Test values for cement (Physical properties)

\begin{tabular}{|cc|}
\hline Name of the test & Test values \\
\hline Specific-gravity & 3.15 \\
Soundness test & $3.3 \mathrm{~mm}$ \\
Fineness (IS sieve 90 microns) & $3 \%$ \\
Standard consistency test & $34 \%$ \\
Initial-setting time & 99 minutes \\
Final-setting time & 254 minutes \\
\hline
\end{tabular}

\section{B. Fine Aggregate:}

The main aim of this research work to minimize the natural materials and replaced in stone dust/quarry dust up to $50 \%$ by weight of fine aggregate (river sand). 
The river sand is passing through IS sieve size of $1.18 \mathrm{~mm}$ sieve and stone dust of fine aggregate passing through the IS sieve size $2.36 \mathrm{~mm}$ and these materials used for casting the concrete and the test values are given in Table II.

Table- II: Test values for aggregates

\begin{tabular}{ccc}
\hline Name of the test & $\begin{array}{c}\text { Test values for } \\
\text { river sand }\end{array}$ & $\begin{array}{c}\text { Test values for } \\
\text { stone dust }\end{array}$ \\
\hline Specific gravity & 2.73 & 2.65 \\
Water absorption & $1.2 \%$ & $1.4 \%$ \\
Rodded density $\left(\mathrm{kg} / \mathrm{m}^{3}\right)$ & 1751 & 1763 \\
\hline
\end{tabular}

\section{Coarse Aggregate:}

The blue metal rough type of crushed stone used as a coarse aggregate and passing through IS sieve of $20 \mathrm{~mm}$ and retained on $12.5 \mathrm{~mm}$. The attained lab test results are represented in Table III.

Table- III: Test values for blue stone (course aggregate)

\begin{tabular}{cc}
\hline Name of the test & Test values \\
\hline Specific gravity & 2.78 \\
Water absorption $(\%)$ & 1.0 \\
Rodded density $\left(\mathrm{kg} / \mathrm{m}^{3}\right)$ & 1830 \\
\hline
\end{tabular}

\section{Fly ash:}

It is rich in $\mathrm{SiO}_{2}, \mathrm{Fe}_{2} \mathrm{O}_{3}$ with $\mathrm{Al}_{2} \mathrm{O}_{3}$ content up to $65 \%$ present in the chemical composition and this type of class ' $\mathrm{F}$ ' fly ash is considered for binding materials in Portland cement following ASTM C618 [21] and image of class F type of fly ash as shown in Figure 1.

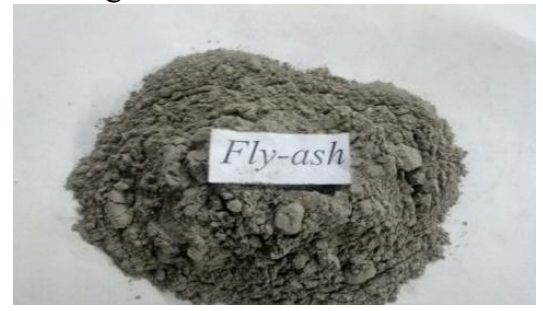

Fig. 1. Image of class F type of fly ash

\section{E. Slag:}

A total of $2.2-3.0$ tons of copper slag is produced approximately while manufacturing of one ton of copper thus a huge amount of waste is partially reused in Portland cement to making the quality of concrete as well as better durability aspects in concrete and image of slag as shown in Figure 2.

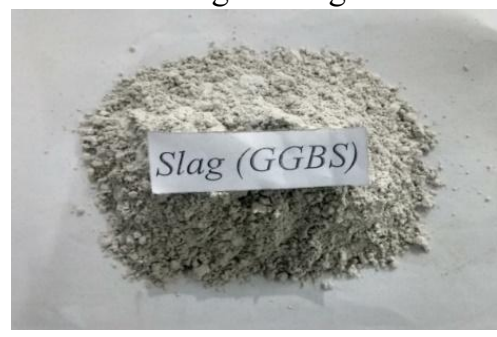

Fig. 2. Image of slag

\section{F. Steel fibres:}

The main important role for the selection of steel fiber is depended on the aspect ratio and has to increase the bending stress in flexural rigidly. The dimension of the fiber having 30 $\mathrm{mm}$ length and $0.5 \mathrm{~mm}$ diameter (aspect ratio is 60 ) were used for various mixes up to $1.5 \%$ of $\mathrm{Vf}$ and image of the crimped type of steel fiber as shown in Figure 3.

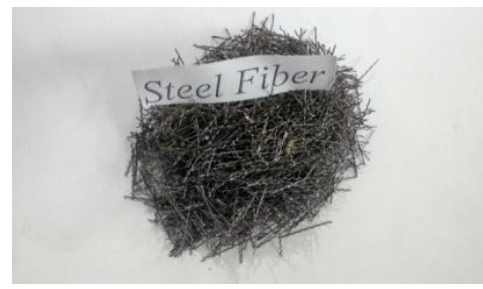

Fig. 3. Image of crimped type steel fibers

\section{G. Rapid hardening admixtures (RHD):}

The detailed specification has given in IS code how to use the low water-cement ratio with help of chemical admixture for various mixes. The RHD (as shown in Figure 4) dosage limits were fixed in the range starting from $1500 \mathrm{ml}$ to 3000 $\mathrm{ml}$ for $50 \mathrm{~kg}$ of Portland cement was noted based on the initial trial and error methods and exhibited the better improvement in fresh concrete.

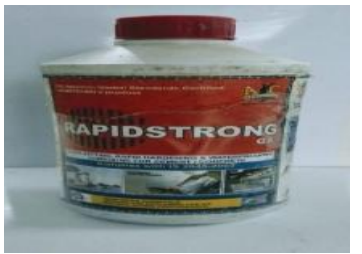

Fig. 4. Image of RHD

\section{H. Curing methods:}

The curing technique method was adopted to increase the high strength in concrete for various mixes. For each sample of specimens cured in normal potable water curing for 7,14 and 28 days after reached the curing the same sample followed by five hours kept in hot air oven curing up to $105-110^{\circ} \mathrm{C}$ before testing on the concrete specimens.

\section{EXPERIMENTAL PROGRAM}

This research work consisting of Eight mixes as represented in Table IV for each mix proportion was calculated for M25 grade of concrete $(1: 1: 2: 0.45)$ in accordance with IS 10262-2019 [22].

Table- IV: Mix proportion details

\begin{tabular}{|c|c|c|c|c|c|c|c|c|}
\hline \multirow{2}{*}{$\stackrel{\text { 离 }}{\stackrel{.}{\mid c}}$} & \multicolumn{3}{|c|}{$\begin{array}{c}\text { Cement required } \\
\mathrm{kg} / \mathrm{m}^{3}\end{array}$} & \multicolumn{2}{|c|}{$\begin{array}{c}\text { Fine } \\
\text { Aggregate } \\
\mathbf{k g} / \mathbf{m}^{3}\end{array}$} & \multirow{2}{*}{ 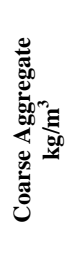 } & \multirow{2}{*}{ 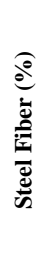 } & \multirow{2}{*}{$\begin{array}{l}\text { RHD } \\
\text { used for } \\
50 \mathrm{~kg} \text { o } \\
\text { cement }\end{array}$} \\
\hline & $\begin{array}{l}\vec{\Xi} \\
\text { Ü }\end{array}$ & $\begin{array}{l}\frac{1}{0} \\
\frac{2}{1}\end{array}$ & $\frac{\text { कू }}{\omega}$ & 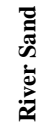 & 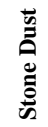 & & & \\
\hline C1 & 420 & 60 & 120 & 300 & 300 & 1200 & 1.5 & 18000 \\
\hline $\mathrm{C} 2$ & 360 & 90 & 150 & 300 & 300 & 1200 & 1.5 & 24000 \\
\hline C3 & 420 & 60 & 120 & 300 & 300 & 1200 & 2 & 18000 \\
\hline $\mathrm{C} 4$ & 360 & 90 & 150 & 300 & 300 & 1200 & 2 & 24000 \\
\hline C5 & 420 & 60 & 120 & 300 & 300 & 1200 & 1.5 & 30000 \\
\hline C6 & 360 & 90 & 150 & 300 & 300 & 1200 & 1.5 & 36000 \\
\hline C7 & 420 & 60 & 120 & 300 & 300 & 1200 & 2 & 30000 \\
\hline C8 & 360 & 90 & 150 & 300 & 300 & 1200 & 2 & 36000 \\
\hline
\end{tabular}




\section{A. Flexural strength test:}

The flexural rigidity in concrete is determined with varying percentage $(0-2 \%)$ use of steel fibre to attain the maximum strength. The size of prism $500 \times 100 \times 100 \mathrm{~mm}$ for cast and tested by third-point loading arrangement was used to determine the bending stress and the dial gauge was read to 1 division on the dial gauge as $1.25 \mathrm{kN}$ of the load. Figure 5 shows the experimental setup for carrying out three-point loading on the beams

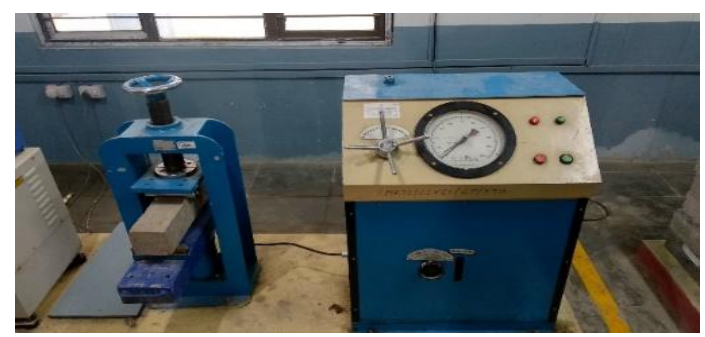

Fig. 5. Three-point loading test setup

\section{B. Ultrasonic Pulse Velocity:}

The non-destructive test (NDT) is performed to calculate the velocity for various mixes by indirect method and test set up as shown in Figure 6 . The beams are divided into 5 equal segments $(5 \times 100=500 \mathrm{~mm})$ on the top surface beam axis to fix the transistor and receiver to record the velocity based on the path length.

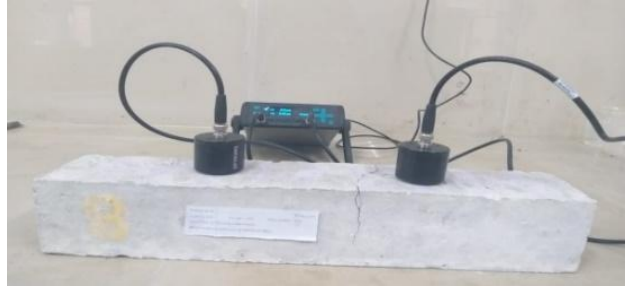

Fig. 6. Image of UPV test set up for indirect method

\section{Crack depth by using UPV:}

Figure 7 shows the schematic line diagram to calculate the crack depth for various mixes and various steps are involved as given in the equation number (1). The RHD chemical admixtures owing to rapid hardening occurred privileged inside the microstructures of concrete, thus indicating the quality of assessment in terms of rate of pulse velocity. Indeed, the recorded values to substitute the equations and calculate the crack depth $(\mathrm{mm})$ for different mixes. Also, manually to measure the crack depth by normal steel scale $(\mathrm{mm})$ and compared all the test results.

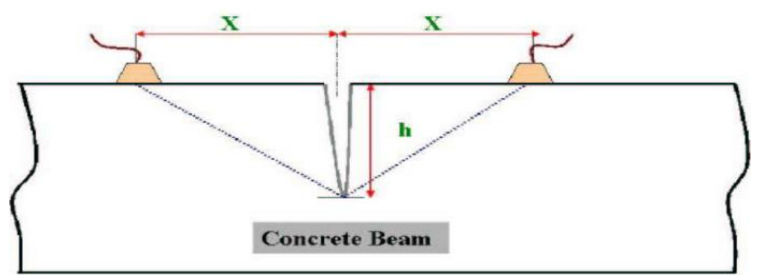

Fig. 7. Schematic line diagram for crack depth measurement in beam
Without crack - path length $=$

$2 x$ \& Surface travel time $\mathrm{Ts}=\frac{2 x}{V}$

Around the crack - path length $=$

$2 \sqrt{x^{2}+h^{2}}$ \& Travel time $T c=\frac{2 \sqrt{x^{2}+h^{2}}}{V}$

$$
\text { Crack depth }(h)=\mathrm{x} \sqrt{(\text { Tc/Ts })^{2}-1}
$$

\section{Modulus of Elasticity of concrete:}

The cylindrical size of concrete specimen height $150 \mathrm{~mm}$ by $300 \mathrm{~mm}$ for diameter was fitted with the compressor meter at the centre of the specimen in the test set up as shown in Figure 8. This experimental test to calculate the secant modulus of concrete by applying the external load gradually for every $5 \mathrm{kN}$ interval up to $40 \%$ of the total failure load and corresponding dial gauge reading was observed. Finally, all values are converted into deflection $(\mathrm{mm})$ for various mixes.

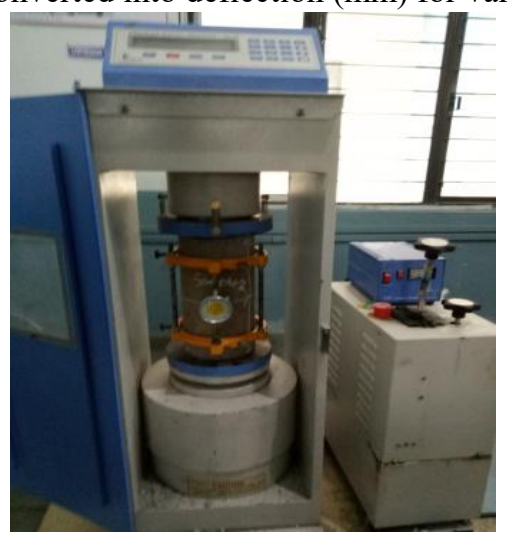

Fig. 8. Modulus of elasticity of concrete test setup

\section{EXPERIMENTAL RESULTS AND DISCUSSION}

\section{A. Flexural strength:}

The bending stress of concrete beams tested for 7,14 and 28 days of curing and test results as shown in Figure 9. The addition of steel fibres which were responsible for the bending moments and flexural strength developed in concrete. The optimum dosage level of steel fibre along with rapid hardening admixture is to increase the bending stress. The best combination of cement is replaced with fly ash $15 \%$ and slag $25 \%$ along with the inclusion of steel fibre $2 \%$ and also added the rapid hardening admixture up to $3000 \mathrm{ml}$ for $50 \mathrm{~kg}$ of cement has produced the maximum flexural rigidity was 4.5 $\mathrm{MPa}$ at 28-days (C8 mix). 


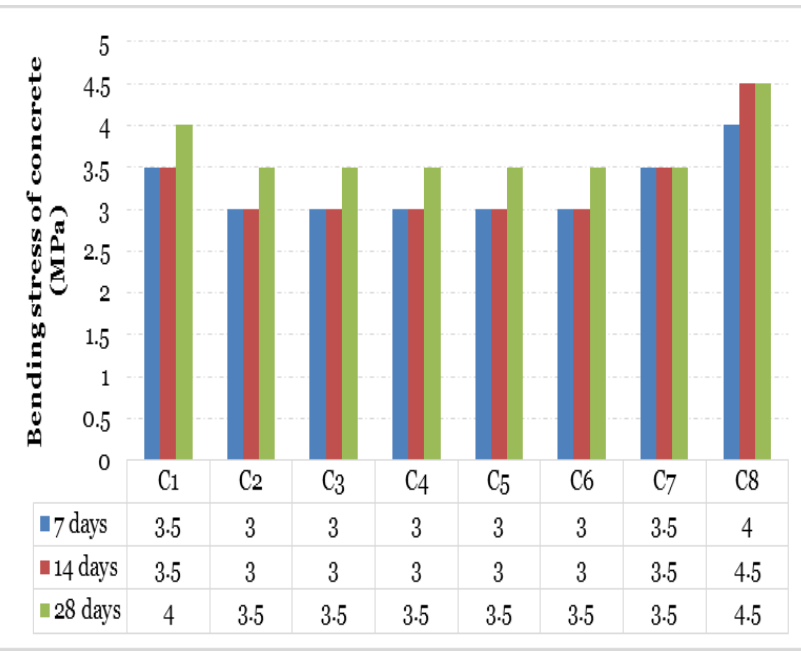

Fig. 9. Bending stress in beam for different curing days

\section{B. Ultrasonic Pulse Velocity:}

The indirect method of determining the pulse velocity was used for the beams. The pulse velocity was measured using a parallel method. As per IS 11331 part 1 [23], the quality of the concrete tested comes under good and excellent rate of conditions. Figure 10 below shows the results of the pulse velocity of beams tested.

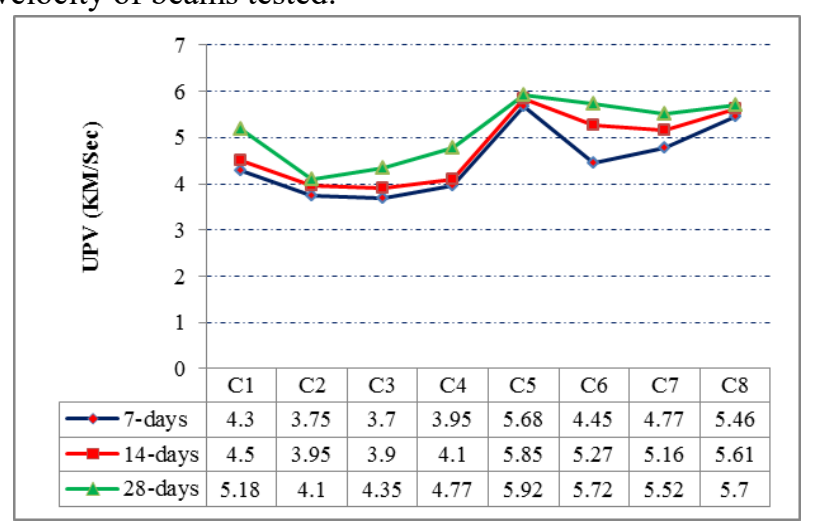

Fig. 10. UPV results for volume reduction

\section{Crack depth in prism by using UPV:}

The maximum bending stress occurred owing to the addition of steel fiber along with chemical admixtures and also material characteristics. This technique is to record the velocity as per IS 13311-1992 part 1 [23] and calculated the crack depth (mm). Figure 11 shows the different test values for manually measured and also using the formula to calculate the crack depth. From the test results shows the higher percentage of slag with fly ash replaced in OPC has calculated depth up to $75 \mathrm{~mm}$ for manual and also $82 \mathrm{~mm}$ was noted by using the UPV than compared to conventional concrete.

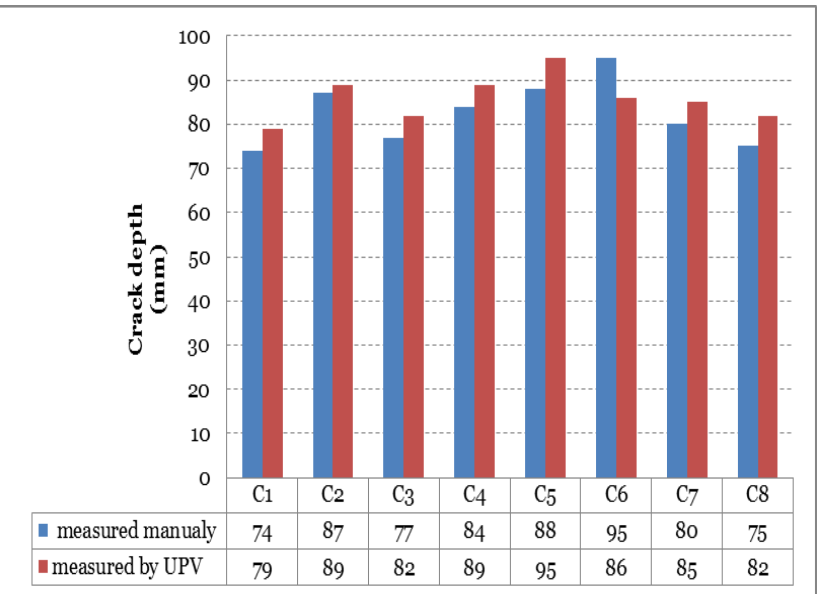

Fig. 11. Crack depth by UPV at 28-days curing

\section{Modulus of Elasticity:}

The modulus of elasticity is found out for the cylinders. The cylinder is fitted to the compressor meter and placed in the compression testing machine, for every $5 \mathrm{kN}$ load is applied and the strain is measured in terms of change in length by reading the dial gauge division multiplied with the least count. The graph shown below was plotted based on stress and strain values which were obtained the test values during the experimental work. The maximum load applied to the cylinder for determining the modulus of elasticity is taken about $40 \%$ of the failure load. The readings were taken up to $220 \mathrm{kN}$ for each mix. The slope of the curve gives the value of elastic modulus of the concrete which was observed to be 23.07 GPa. Figure 12 shows the graph drawn from the stress and strain values obtained.

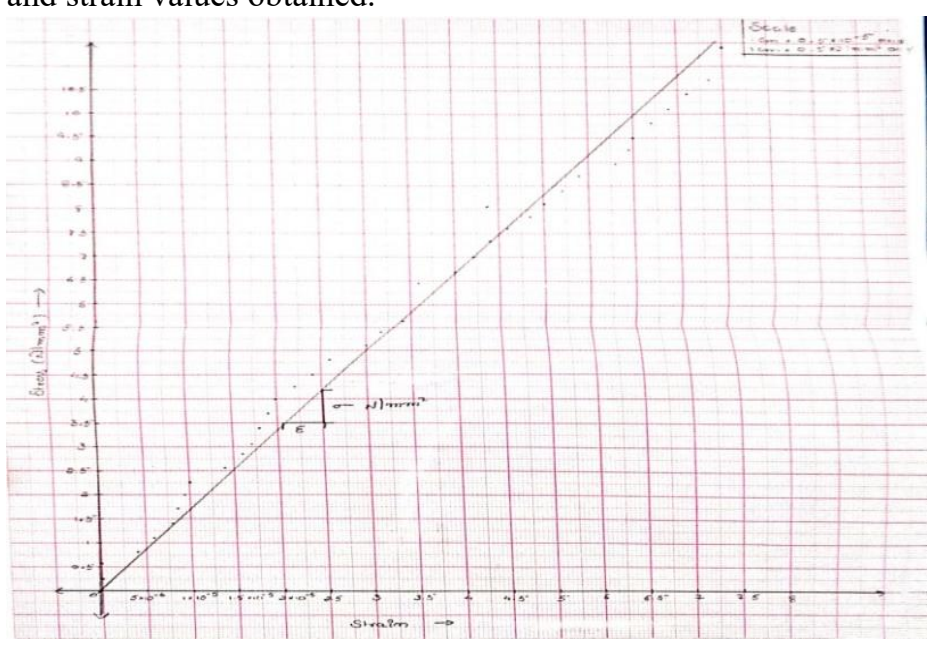

Fig. 12. Graphically representation of stress and strain curve for scant modulus

\section{CONCLUSION}

The following conclusions were drawn from the experimental limitations of the study.

- Increase in the volume of steel fibre to reach the maximum bending stress and attained the target mean strength was 3.5 $\mathrm{N} / \mathrm{mm}^{2}$ at 7 -days of curing.

- No change occurred in the flexural strength in concrete beam having $0 \%$ of steel fiber reinforced concrete. 
- Steel fibre contributes to limitation of initial cracks, bridging the gap and increases the bending stress and also pull-out resistance capacity.

- The elastic modulus of concrete represents good strength and reduction in the deterioration of concrete, as obtained $92.28 \%$ of elastic modulus for 7-days of curing.

\section{REFERENCES}

1. Lubos Pazdera, Libor Topolar, Jaroslav Smutny, and Kristyna Timcakova 2015 Non-destructive Testing of Advanced Concrete Structure during Lifetime Advances in Materials Science and Engineering 2015 pp 1- 5 http://dx.doi.org/10.1155/2015/286469

2. Byung Jae Lee, Seong-Hoon Kee Taekeun Oh and Yun-Yong Kim 2015 Effect of Cylinder Size on the Modulus of Elasticity and Compressive Strength of Concrete from Static and Dynamic Tests Advances in Materials Science and Engineering 2015 pp 1-12 http://dx.doi.org/10.1155/2015/580638

3. Srinivasan Karunanithi and Sivakumar Anandan 2014 Flexural Toughness Properties of Reinforced Steel Fibre Incorporated Alkali Activated Slag Concrete Advances in Civil Engineering 2014 pp 1-12 http://dx.doi.org/10.1155/2014/719436

4. Piero Colajanni, Maurizio Papia and Nino Spinella 2013 Stress-Strain Law for Confined Concrete with Hardening or Softening Behaviour Advances in Civil Engineering 2013 pp 1-11 http://dx.doi.org/10.1155/2013/804904

5. Sanjeev Kumar Verma Sudhir Singh Bhadauria and Saleem Akhtar 2013 Review of Non-destructive Testing Methods for Condition Monitoring of Concrete Structures Journal of Construction Engineering 2013 pp 1-11 http://dx.doi.org/10.1155/2013/834572

6. Tan Chien Yet, Hamid R and Mudiono Kasmuri 2012 Dynamic Stress-Strain Behaviour of Steel Fiber Reinforced High-Performance Concrete with Fly Ash Advances in Civil Engineering 2012 pp 1- 6 doi:10.1155/2012/907431

7. Jikai Zhou, Pingping Qian and Xudong Chen 2014 Stress-Strain Behaviour of Cementitious Materials with Different Sizes The Scientific World Journal $2014 \quad$ pp $1-11$ http://dx.doi.org/10.1155/2014/919154

8. Loan T Q, Ngo Yu-Ren Wang and Yi-Ming Chen 2018 Applying Adaptive Neural Fuzzy Inference System to Improve Concrete Strength Estimation in Ultrasonic Pulse Velocity Tests. Advances in Civil Engineering 2018 pp 1-11 https://doi.org/10.1155/2018/2451915

9. Baek-IlBae, Hyun-Ki Choi and Chang-Sik Choi 2016 Flexural Strength Evaluation of Reinforced Concrete Members with Ultra High Performance Concrete Advances in Materials Science and Engineering 2016 pp1-10 http://dx.doi.org/10.1155/2016/2815247

10. Fang-Yuan Li, Cheng-Yuan Cao, Yun-Xuan Cui, and Pei-Feng Wu 2018 Experimental Study of the Basic Mechanical Properties of Directionally Distributed Steel Fibre-Reinforced Concrete Advances in Materials Science and Engineering 2018 pp 1-11 https://doi.org/10.1155/2018/3578182

11. Seungho Cho1 and Seunguk Na 2018 Evaluation of the Flexural Performance and CO2 Emissions of the Voided Slab Advances in Materials Science and Engineering 2018 pp 1-13 https://doi.org/10.1155/2018/3817580

12. Kwang-MyongLee, SungChoi JinkyoF.Choo Young-CheolChoi and Sung-WonYoo4 2017 Flexural and Shear Behaviours of Reinforced Alkali-Activated Slag Concrete Beams Advances in Materials Science and Engineering 2017 pp 1-12 https://doi.org/10.1155/2017/5294290

13. Jason Maximino C Ongpeng Andres Winston C Oreta and Sohichi Hirose 2018 Contact and Noncontact Ultrasonic Non-destructive Test in Reinforced Concrete Beam Advances in Civil Engineering 2018 pp1-10 https://doi.org/10.1155/2018/5783175

14. In-Hwan Yang, Changbin Joh and Kyoung-Chul Kim 2018 A Comparative Experimental Study on the Flexural Behaviour of High-Strength Fiber-Reinforced Concrete and High-Strength Concrete Beams Advances in Materials Science and Engineering 2018 pp 1-13 https://doi.org/10.1155/2018/7390798

15. Varma M B and Pujari R S 2011 Flexural Strength of Concrete Beam Reinforced with GFRP Rebar. International Journal of Earth Sciences $\begin{array}{lllll}\text { and Engineering } & 04 & \text { (6) } & \text { pp } & 994-996\end{array}$ https://www.researchgate.net/publication/322306849

16. Ashwin Balwaik, S.: Efficiency of Ultrasonic pulse velocity test in life of concrete structure. IOSR Journal of Mechanical and Civil Engineering 12 pp 01-06 www.iosrjournals.org
17. Binaya Patnaik, Seshadri Sekhar T and Chandra Sekhar B 2015 An experimental investigation on strength properties of copper slag fiber reinforced concrete ARPN Journal of Engineering and Applied Sciences 10 pp 9246- 9257

18. Priyanka Ramakripal Singh Aishwarya Goel Shailendra Thakur and Shah N D 2016 An Experimental Approach to Investigate Effect of Steel Fibers on Tensile and Flexural Strength of Fly ash Concrete International Journal of Scientific Engineering and Applied Science 2(5) pp 384-392

19. Arun G 2018 Experimental Investigation on Flexural Behavior of Reinforced Concrete Beams Containing Copper Slag, Fly-Ash and Steel Fibers International Research Journal of Engineering and Technology 05(6) pp 420-422

20. Prince, Aditya kumar and Tiwary 2018 Effect of Copper Slag and Fly ash on Mechanical Properties of Concrete International Journal of Civil Engineering and Technology 9 pp $354-362$ http://www.iaeme.com/ijciet

21. IS ASTM C618 Standard Specification for Coal Fly Ash and Raw or Calcined Natural Pozzolan for Use in Concrete

22. IS 10262-2019 Indian standard concrete mix proportioning guidelines

23. IS 13311 Part 1 (1992) Non-destructive testing of concrete - methods of test part 1 ultrasonic pulse velocity

\section{AUTHORS PROFILE}

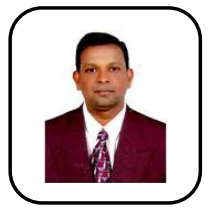

Dr VM Sounthararajan working as a Professor in the Department of Civil Engineering at CMR Technical Campus, Hyderabad, Telangana. He has 9.5 years teaching as well as research experience. Also, eight years of Industrial experience. He is a reviewer for more than four reputed journals. He is a Member of Indian Society for Technical Education. He has received the best research awards at VIT University in the year of 2012 and 2013. He has published more than fifty-two research papers in various National and International journals and conferences.

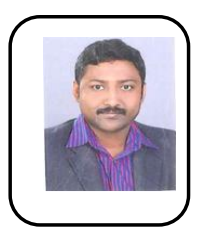

Dr. S. Sivasankar is presently working as an Associate professor in the Department of Civil Engineering, CMR Technical Campus, Hyderabad, Telangana. He has eight years of teaching experience and one year industry experience. Also he has four years of research experience. He published ten research articles in national and international journals. His research area includes steel-concrete composites, strengthening and retrofitting of steel and concrete structures and corrosion assessment in steel and concrete. $\mathrm{He}$ is a life member in ISTE, IAE and IE chapters.

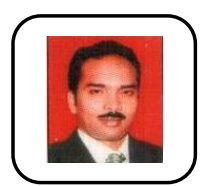

Dr. T.L. Ramadasu, working as a Professor in Department of Civil Engineering, CMR Technical Campus, Hyderabad, Telangana, India. He has 16 years of teaching experience and one year in industry. He has published 24 research papers in various National and International Journals and conferences. He is a life member in various chapters like ISTE, IGS, IEI and Chartered engineer. 